\title{
Thin layer measurement of soil bulk density
}

\author{
GARY W. FRASIER AND JENNIFER KEISER
}

\begin{abstract}
Authors are research hydraulic engineer, USDA-ARS, Rangeland Resources Research Unit, 1701 Center Ave., Fort Collins, Colo. 80526; and student research technician, Colorado State University, Range Science Department, Fort Collins 80523.
\end{abstract}

\begin{abstract}
Measurement of soil bulk densities is difficult if there are gravel, stones, or other materials present in the soil profile. A technique is offered for estimating the soil bulk density in thin layers $(1.0 \mathrm{~cm})$ in loose, nonuniform soils with low moisture levels. The technique consists of the removal of the soil in shallow layers. As each layer is removed, the hole is filled with a molten paraffin wax to obtain a casting of the excavated volume. Measured bulk densities values using this procedure compare well to results obtained with other techniques.
\end{abstract}

\section{Key Words: infiltration, paraffin wax, soil texture}

Bulk density is an important soil characteristic which affects many biological and physical processes, such as root penetrations and water infiltration. Soil bulk density of field sites is frequently estimated by driving a cylinder of known volume into the ground to obtain a soil core. Other techniques utilize a balloon or other flexible lining placed in the excavated hole and filled with a measured volume of water or dry sand. The removed soil is dried and weighed (Blake 1965). These techniques provide a measure of the average bulk density for a volume of soil several centimeters deep. The procedures are reasonably simple and easy, giving reproducible results in homogeneous soils if: (1) the soil water content is in the range where there is no change in soil core volume as a sampler is inserted; (2) the soil texture allows insertion of the sampler, i.e., no rocks or stones in the profile to hit the cutting edge of the sampler; and (3) the balloon or lining material does not dislodge soil particles when being inserted and conforms to the minor surface irregularities. These techniques are not satisfactory on many soils where there are gravel, stones, or other material in the profile or for sampling at the soil surface when the soil is dry and loose. A technique is described that allows the estimation of soil bulk density in thin layers $(1.0 \mathrm{~cm})$ in loose soils which may also have imbedded material such as gravel and rocks or is composed of other non-uniform material. The accuracy of the technique is compared to other bulk density techniques.

\section{Methods and Materials}

The technique involves the removal of the soil in shallow layers. As each layer is removed, the hole is filled to the original soil level of the layer with a molten paraffin wax. After the wax has solidified, the wax casting is removed and weighed. The volume of the wax is then calculated based on the wax specific density. The soil removed from the hole is dried and weighed.

\section{Procedure}

The soil in the sampling area is removed to the required depth

These studies were conducted in the summer of 1992. Shortly after acceptance of the paper for publication the authors became aware of the studies by Muller and Hamilton (1992) which uses an expanding urethane foam in a similar conceptual approach. We do not wish to detract from the earlier published studies and believe the techniques are complementary.

Manuscript accepted 13 Sept. 1992. and stored in a plastic bag for later drying and weighing. After the hole has been excavated, molten paraffin wax is carefully poured into the depression, filling to the original soil surface of the layer. It is critical that the temperature of the wax be as close to the solidifying temperature as possible. If the wax is too hot, pouring may disturb the soil particles resulting in incorporation of soil into the wax casting. Also, cooler wax will not flow into the pores of the surrounding soil, which can occur if the wax temperature is too hot. At the optimum temperature, the wax will begin to solidify and change from colorless to white immediately upon contact with the soil surface. The wax temperature can be checked by pouring a small amount into a test soil depression in the area. It is best to use wax with a melting point of $53^{\circ} \mathrm{C}$ or higher. On summer days when soil temperatures are hot, low melting point waxes are slow to solidify and the castings are soft and may deform when being removed from the soil or transported.

After the wax has solidified, the casting is removed from the hole. Soil particles clinging to the wax casting are rinsed off with cool water $\left(18-22^{\circ} \mathrm{C}\right)$ and brushed away. Wax shrinks as it cools which leaves a depression in the top surface. Molten wax is poured into the depression in sufficient quantity to "bead" above the surface. After the wax has cooled, the excess wax above the sides of the original sample is removed using a sharp knife (Fig. 1). This can be done at a later time.

The volume of the wax casting is determined by dividing the weight of the wax casting by the density of the paraffin wax. The specific density for paraffin wax varies from 0.87 to $0.91 \mathrm{~g} / \mathrm{cm}^{3}$ (Weast et al. 1965). The density of the wax used can easily be determined by filling a known volume container with molten wax. The specific density is the weight of the cooled wax per unit volume.

The soil removed from the hole is dried at $105^{\circ} \mathrm{C}$ for 24 hours and then weighed. The soil bulk density is the weight of the soil per unit volume of wax. The procedure is repeated as necessary for deeper layers in the soil profile.

\section{Evaluation Procedure:}

Laboratory-The procedure was initially compared to the cor-

Table 1. Comparison of bulk density measurements of laboratory prepared samples using wet 70 mesh silica sand with a known bulk density.

\begin{tabular}{|c|c|c|c|}
\hline & \multicolumn{3}{|c|}{ Tray } \\
\hline & 1 & 2 & 3 \\
\hline & \multicolumn{3}{|c|}{ 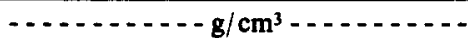 } \\
\hline Average bulk density of tray & 1.50 & 1.32 & 1.44 \\
\hline Core & 1.59 & 1.50 & 1.55 \\
\hline Wax-Subset A & 1.18 & 1.18 & 1.20 \\
\hline $\mathbf{B}$ & 1.45 & 1.28 & 1.33 \\
\hline C & 1.32 & 1.23 & 1.31 \\
\hline Mean (wax) & 1.32 & 1.23 & 1.28 \\
\hline Std. Dev. (wax) & .14 & .05 & .07 \\
\hline
\end{tabular}




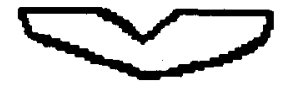

OR I G I NAL

WAX

CASTING

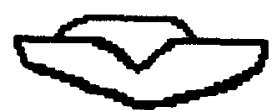

WAX CASTING

WI TH

BEAD

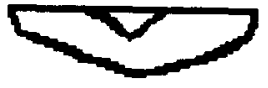

SHAVED
WAX
BEAD CASTING

Fig. 1. Sketch of wax castings.

Table 2. Comparison of bulk density measurements of laboratory prepared samples using dry 70 mesh silica sand with a known bulk density.

\begin{tabular}{|c|c|c|c|c|c|c|}
\hline & \multicolumn{6}{|c|}{ Tray } \\
\hline & 1 & 2 & 3 & 4 & 5 & 6 \\
\hline & $\ldots$ & 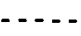 & 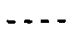 & $\cdots$ & $\ldots . .$. & $\ldots$ \\
\hline Average bulk density of tray & 1.32 & 1.32 & 1.36 & 1.36 & 1.34 & 1.37 \\
\hline Wax-Subset A & 1.46 & 1.46 & 1.26 & 1.59 & 1.28 & 1.17 \\
\hline B & 1.35 & 1.21 & 1.25 & 1.21 & 1.17 & 1.12 \\
\hline $\mathrm{C}$ & 1.31 & 1.28 & 1.42 & 1.20 & 1.19 & 1.29 \\
\hline D & 1.23 & 1.31 & 1.41 & 1.17 & 1.33 & 1.28 \\
\hline Mean (wax) & 1.34 & 1.32 & 1.34 & 1.29 & 1.24 & 1.22 \\
\hline Std. Dev. (wax) & 0.10 & 0.11 & 0.09 & 0.20 & 0.08 & 0.08 \\
\hline
\end{tabular}

ing method on 70 mesh silica sand dampened with sufficient water to make the sand particles cohesive. Small plastic trays, $12.5-\times$ 13.5- $\times 3.5-\mathrm{cm}$ were filled with silica sand and wetted with approximately 100 grams of water. The average bulk density of the sand in the tray was based on the total dry sand per tray. In each tray, the bulk density of the top $1 \mathrm{~cm}$ layer was measured at 3 locations using the paraffin wax technique. Also, a $4.9-\mathrm{cm}$ diameter $\times 3.0-\mathrm{cm}$ long core of wetted sand was extracted with a thin wall core sampler. The size of the trays limited the number of core samples that could be taken. Both sets of measurements were repeated in 3 separate trays.

The paraffin wax technique was then tested on dry silica sand that was not wetted. The bulk density of the top $1 \mathrm{~cm}$ layer was measured at 4 locations within each tray. These measurements were replicated in 6 separate trays. The absence of soil moisture made it impossible to use the core sampler.

Field-The technique was field evaluated on a test area at the Central Plains Experimental Range near Nunn, Colo. The area had previously been plowed and leveled into a bench terrace $(6.5-\mathrm{m}$ wide and $175-\mathrm{m}$ long) in preparation for another project. The soil is an Ascalon series gravelly loamy sand that had been thoroughly mixed in the top 60 -cm approximately 6 months prior to sampling.
Four areas, 3-m $\times 3-\mathrm{m}$, were randomly located on the terrace. Two of the areas were sampled on 1 day and the remaining 2 sampled 7 days later. The soil surface of the area was dry and hard. To facilitate sampling, the soil was sprinkled with sufficient tap water to wet to a $3-\mathrm{cm}$ depth. A 4.9-cm diameter $\times 3.0-\mathrm{cm}$ long core sample was taken with a thin wall sampler on the prewetted soil surface in each test area. Three adjacent locations were sampled using the wax technique. The wax sample areas are identified as small-wet, large-wet, and large-dry. Areas designated as wet were prewetted by spraying sufficient water on the soil surface to penetrate $2-3 \mathrm{~cm}$. The "small" samples were $4-\mathrm{cm}$ diameter and the "large" samples were $8-\mathrm{cm}$ diameter. Samples were initially taken on the 0-1 cm depth range. After removal of 0-1 cm depth layer wax casting, a second measurement representing the 1-3 cm depth was taken using the bottom of the hole from the first sample as the top of the second layer. Only the surface $0-1 \mathrm{~cm}$ layer was sampled in the dry state.

\section{Results and Discussion}

\section{Laboratory}

The bulk density values determined by both the wax casting

Table 3. Comparison of bulk density measurements on a sandy loam field site.

\begin{tabular}{|c|c|c|c|c|c|c|}
\hline \multirow[b]{2}{*}{ Method } & \multirow[b]{2}{*}{ Size } & \multirow[b]{2}{*}{ Depth } & \multicolumn{4}{|c|}{ Replicate } \\
\hline & & & 1 & 2 & 3 & 4 \\
\hline & & $\mathrm{cm}$ & $\ldots \ldots$ & $\ldots$ & $-\cdots$ & $-\ldots$ \\
\hline Core & & $0-3$ & 1.24 & 1.32 & 1.28 & 1.23 \\
\hline \multirow[t]{3}{*}{ Wax } & Small' Wet & $0-1$ & 1.30 & 1.10 & 1.28 & 1.05 \\
\hline & Large $^{2}$ Wet & $0-1$ & 1.65 & 1.06 & 1.19 & 1.20 \\
\hline & Large Dry & $0-1$ & 0.77 & 1.10 & 1.31 & 1.01 \\
\hline \multicolumn{2}{|c|}{ Mean (wax) } & $0-1$ & 1.24 & 1.09 & 1.26 & 1.09 \\
\hline \multicolumn{2}{|c|}{ Std. Dev. (wax) } & $0-1$ & 0.44 & 0.02 & 0.06 & 0.10 \\
\hline \multirow[t]{2}{*}{ Wax } & Small Wet & $1-3$ & 1.36 & 1.22 & 1.14 & 1.64 \\
\hline & Large Wet & $1-3$ & 1.34 & 1.21 & 1.29 & 1.21 \\
\hline \multicolumn{2}{|c|}{ Mean (wax) } & $1-3$ & 1.35 & 1.22 & 1.23 & 1.43 \\
\hline \multicolumn{2}{|c|}{ Std. Dev. (wax) } & $1-3$ & 0.01 & 0.01 & 0.11 & 0.30 \\
\hline
\end{tabular}

ISmall $=4 \mathrm{~cm}$ diameter samples

${ }^{2}$ Large $=8 \mathrm{~cm}$ diameter samples 
technique and the thin wall core sampler on the prewetted sand were within 2 standard deviations of the average bulk density of the tray (Table 1). Core measured bulk densities were expected to be higher than the bulk densities determined using the wax method due to compaction of the sand from insertion of the coring tool. It is also possible that the surface layer had a lower bulk density than the "average" for the entire depth.

Bulk density measurements of dry sand were within 1 to 2 standard deviations of the mean bulk density of the tray (Table 2). Bulk density measurements with the wax technique were often lower than the average bulk density of the tray because of a tendency not to remove enough of the excess wax and possibly because the top $1 \mathrm{~cm}$ of the sand had a lower bulk density.

\section{Field}

As expected for field sites, all techniques resulted in variations in the measured bulk densities. Soil surface $(0-1 \mathrm{~cm})$ bulk densities with the wax technique were approximately within 1 to 2 standard deviations of the core sampling technique bulk densities (Table 3). It was expected that the wax measured bulk densities would be lower than the core measured bulk densities because the core measurements represented the $0-3 \mathrm{~cm}$ depth and the wax technique measured the upper layer which is normally less dense. In the 1-3 $\mathrm{cm}$ layer, the wax measured bulk densities were similar to the core sampled measurements. The variability in the measured bulk den- sity values were similar to the variability reported in other studies (Fritton and Olson 1972).

\section{Summary}

The wax casting technique is an effective way of obtaining a measure of soil bulk density in loose and dry soils where other techniques are limited or ineffective. The wax technique is also suitable for obtaining bulk density values at micro locations within the soil profile. This is important in applications such as evaluating the effect of soil layering on water infiltrations or plant root penetration.

\section{Literature Cited}

Blake, G.R. 1965. Bulk density. p. 374-390. In: C.A. Black (ed.) Methods of soil analysis, Part 1, Physical and mineralogical properties including statistics of measurement and sampling. No. 9, Agronomy. Amer. Soc. of Agron., Madison, Wisc.

Fritton, D.D., and G.W. Olson. 1972. Bulk density of a fragipan soil in natural and disturbed profiles. Soil Sci. Soc. Amer. Proc. 36:686-688.

Muller, Robert N., and Milinda E. Hamilton. 1992. A simple, effective method for determining the bulk density of stoney soils. Commun. Soil Sci. Plant Anal. 34:313-319.

Weast, Robert C., Samuel M. Selby, and Charles D. Hodgman. (eds.) 1965. Handbook of Chemistry and Physics. 46th Ed. The Chemical Rubber Co., Cleveland, Ohio. 